\title{
Moving marine microplastics
}

Plastic pollution is ubiquitous in the marine environment, with over 10 million tons exported into the oceans each year. The majority of the plastic (>99\%) is likely stored in the deep sea, with high concentrations ending up in submarine canyons. However the mechanism of transport to these features is unknown. One hypothesis is that gravity-driven flows, known as turbidity currents (which move sediment and organic matter thousands of kilometres over the sea floor), also move microplastics.

Florian Pohl of Utrecht University, Netherlands, and Durham University, U.K., and colleagues investigated microplastic transport to and through submarine canyons via turbidity currents. Quartz sand was mixed with microplastic fragments and fibres and released in a flume tank designed to simulate field-scale turbidity currents. The results demonstrated that microplastics can be transported

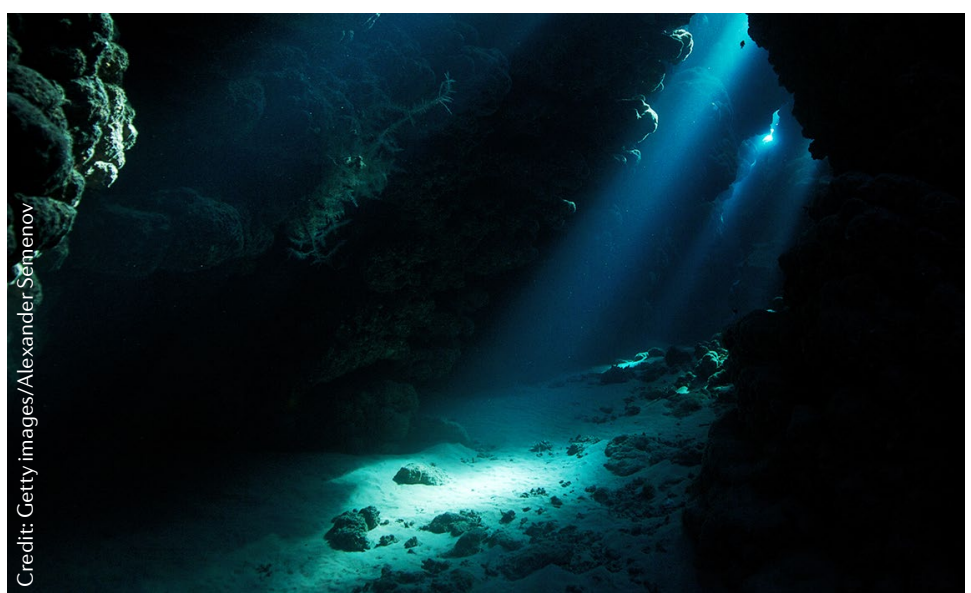

and deposited by turbidity currents. Fragment concentrations were more stratified in the current than were the fibres, which settle more slowly because of their larger surface to volume ratio and are thus more evenly distributed. Surprisingly, fibres were found to be preferentially buried within the resultant deposits, which was attributed to the trapping of fibres by sand particles that rapidly fall out of suspension.

While designed to simulate several aspects of field-scale turbidity currents, the flume experiments did not include clays, which are more cohesive than sand and could influence microplastic movement and deposition. Nevertheless, it is clear than turbidity currents have the potential to transport large quantities of plastic pollution from nearshore environments into the deep sea, where it can impact local ecosystems.

Laura Zinke

ORIGINAL ARTICLE Pohl, F. et al. Transport and burial of microplastics in deep-marine sediments by turbidity currents. Environ. Sci. Technol. https:// doi.org/10.1021/acs.est.9b07527 (2020) 